\title{
Análise dos relatórios de auditoria sobre as demonstrações contábeis das companhias listadas na B3 em 2019
}

\section{Analysis of the audit reports on the financial statements of the companies listed at} B3 in 2019

\section{RESUMO}

O relatório de auditoria é o resultado do trabalho do auditor independente, no qual expressa uma opinião sobre as demonstrações contábeis da companhia. Dito isso, o presente estudo teve como objetivo geral: analisar os relatórios de auditoria sobre as demonstrações contábeis das companhias listadas na B3 referentes ao exercício de 2019. Classificou-se o estudo como um levantamento de dados para fins exploratórios e descritivos (survey) na área de conhecimento da Auditoria. O objeto de estudo são os relatórios de auditoria independente sobre as demonstrações contábeis das empresas de capital aberto com ações negociadas na B3 referentes ao exercício de 2019 emitido até março de 2020, cuja totalidade desses relatórios refere-se a 403. Verificou-se que a maioria dos relatórios com opinião não modificada e com opinião com ressalva foram emitidos por firmas Big Four. Por outro lado, as abstenções de opinião foram emitidas, em sua maior parte, por firmas não Big Four. Destaca-se também que 230 das 403 companhias auditadas são dos setores Financeiro, de Consumo Cíclico e de Bens Industriais. Entretanto, apenas os setores de Comunicações, Saúde, Tecnologia da Informação e Outros foram os únicos nos quais não houve a emissão de opinião modificada. As investigações de autoridades públicas, a exclusão do ICMS da base de cálculo do PIS e COFINS e as incertezas relativas à continuidade operacional motivaram uma parcela considerável das ressalvas. Além disso, a recuperação judicial e as incertezas relativas à continuidade operacional foram as bases para abstenção de opinião mais frequentes.

Palavras-chave: relatório de auditoria; demonstrações contábeis; companhias abertas; opinião

\section{ABSTRACT}

The audit report is the result of the work of the independent auditor, in which he expresses an opinion on the company's financial statements. That said, the present study had as its general objective: to analyze the audit reports on the financial statements of the companies listed in B3 for the 2019 financial year. The study was classified as a survey of data for exploratory and descriptive purposes (survey) in Audit knowledge area. The object of the study is the independent audit reports on the financial statements of publicly traded companies with

\footnotetext{
${ }^{1}$ Graduando em Ciências Contábeis pela Universidade Estácio de Sá/PE. Brasil. E-mail: i.vianavital@gmail.com

2 Mestre em Ciência Contábeis pela Universidade Federal de Santa Catarina. Brasil. E-mail: stephaniekrocha@gmail.com
} 
shares traded on B3 for the year 2019 issued until March 2020, the total of which reports refer to 403. It was found that the most of the reports with unmodified opinion and with qualified opinion were issued by Big Four firms. On the other hand, opinion abstentions were issued, for the most part, by non-Big Four firms. It is also worth mentioning that 230 of the 403 audited companies are from the Financial, Cyclical Consumption and Industrial Goods sectors. However, only the Communications, Health, Information Technology and Others sectors were the only ones in which there was no modified opinion. Investigations by public authorities, the exclusion of ICMS from the PIS and COFINS calculation base and the uncertainties related to operational continuity motivated a considerable part of the reservations. In addition, judicial recovery and uncertainties related to operational continuity were the most frequent basis for abstaining from opinion.

Keywords: audit report, accounting statements, publicly-held companies, opinion

\section{INTRODUÇÃO}

Dentre o conjunto de exigências legais da auditoria independente, a Lei $\mathrm{n}^{\circ}$ 6.404/76, que dispõe sobre as Sociedades por Ações, determina que as demonstrações financeiras das companhias abertas devem ser submetidas à auditoria por auditores independentes registrados na Comissão de Valores Mobiliários. Por seu turno, a Comissão de Valores Mobiliários, por meio da Instrução $\mathrm{n}^{\mathrm{o}} 308$ de 1999, estabeleceu normas sobre o registro e exercício da auditoria independente e os deveres e responsabilidades das entidades auditadas no relacionamento com os auditores independentes (ALMEIDA, 2019).

Destaca-se, entretanto, que exigência legal não é a única razão para a prática das atividades de auditoria independente dado que a auditoria externa exerce papel essencial na atração de parceiros e investimentos mediante incremento da credibilidade da companhia junto a bancos e fornecedores e por proporcionar uma visão externa sobre ela quanto ao setor de atuação, modelo de gestão e aos riscos aos quais a companhia se sujeita (GARÇON, 2012).

Em outras palavras, assume sua importância no tocante à necessidade de transparência e neutralidade de dados em uma economia de livre mercado, no qual exige-se que as informações divulgadas nas demonstrações das companhias reflitam adequadamente as condições econômicas dos seus recursos controlados e das obrigações devidas, bem como a natureza das transações realizadas (GRAMLING et al., 2011).

A materialização final de um trabalho de auditoria é o parecer ou relatório do auditor independente, um documento público mediante o qual expressa uma opinião sobre as demonstrações contábeis de uma companhia. Logo, este documento é de grande 
responsabilidade para o auditor, uma vez que, caso seja emitido de forma inadequada, o profissional pode incorrer em sanções penais e civis (DAMASCENA et al., 2011).

Diante do exposto, o presente estudo teve como objetivo geral: analisar os relatórios de auditoria sobre as demonstrações contábeis das companhias listadas na B3 referentes ao exercício de 2019. Os objetivos específicos foram: classificar os relatórios de auditoria independente sobre as demonstrações das companhias negociadas na B3 referentes ao exercício de 2019 com opiniões modificadas e não modificadas por firmas Big Four e não Big Four, e por setor de atuação, bem como expor os fatores mais frequentes que motivaram a emissão de relatórios de auditoria independente com opinião modificada.

A contribuição deste estudo consiste em oferecer aos investidores, administradores, órgãos reguladores e, especialmente, aos profissionais da área de auditoria independente um diagnóstico atualizado e consolidado a respeito dos relatórios sobre as demonstrações contábeis das companhias listadas na B3 referentes ao exercício de 2019. Deste modo, o estudo poderá servir, por exemplo, como ferramenta de apoio na aceitação de clientes, no planejamento do trabalho do auditor, na determinação dos procedimentos de auditoria e nas demais tomadas de decisões. Ressalta-se ainda a relativa escassez de produção bibliográfica no Brasil quanto ao tema.

\section{REFERENCIAL TEÓRICO}

\subsection{Auditoria Independente}

De acordo com a NBC TA 200, o auditor das demonstrações contábeis objetiva emitir sua opinião sobre a conformidade da elaboração dessas demonstrações com uma estrutura de relatório financeiro aplicável, em todos os seus aspectos relevantes.

Para isto, exige-se que a auditoria seja feita com um planejamento adequado e proceda-se à avaliação do controle interno da entidade e à realização de revisões analíticas das contas, o que propicia a execução de procedimentos de auditoria, permitindo a avaliação das evidências encontradas para a emissão do parecer (ALMEIDA, 2019). O fluxograma dessas etapas pode ser visualizado na figura 1. 
Figura 1: Etapas da auditoria das demonstrações contábeis

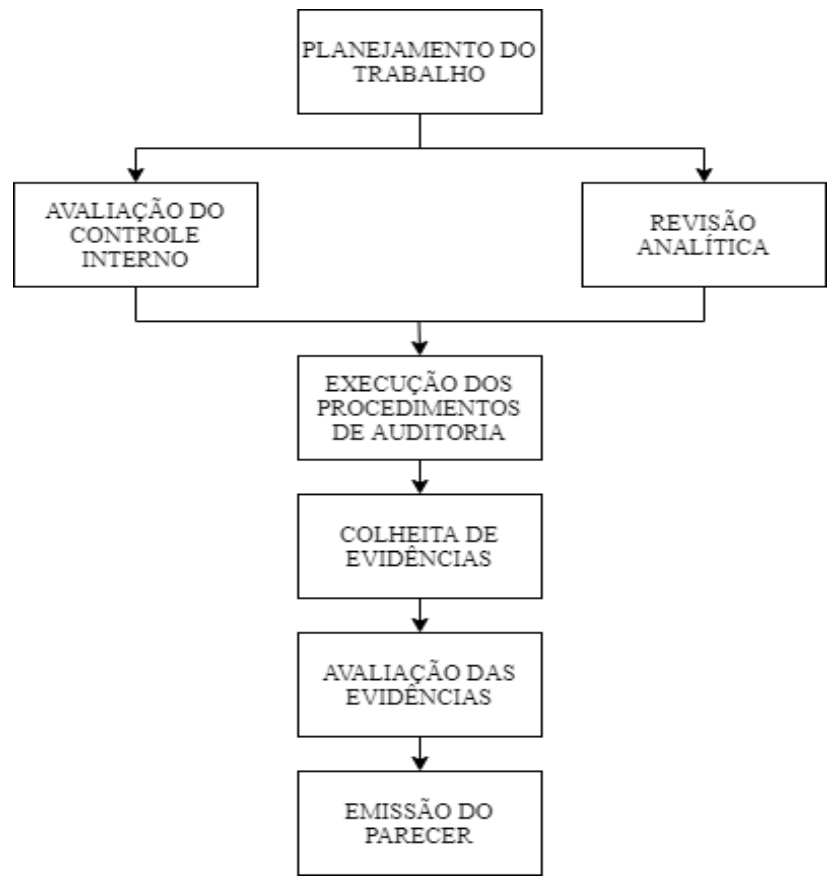

Fonte: Adaptado de Almeida, 2019.

O auditor independente deve exercer suas atividades com independência, sigilo, ceticismo e julgamento profissionais, atendendo aos seguintes princípios éticos: integridade, objetividade, competência e zelo profissional, confidencialidade e conduta profissional (LEONE, 2018).

As entidades obrigadas à sujeição de suas demonstrações contáveis à auditoria independente são as sociedades anônimas de capital aberto, instituições financeiras, companhias de seguros, fundos de previdência complementar, fundações públicas e privadas de interesse público, empresas subordinadas a agências reguladoras e sociedades de grande porte (CREPALDI, CREPALDI, 2019).

As vantagens da auditoria independente para a administração da empresa residem, por exemplo, na asseguração da maior correção dos registros contábeis, na identificação de falhas na organização administração e nos controles internos da empresa, e na obtenção de melhores informações sobre a real situação econômica, patrimonial e financeira da empresa. Para os investidores, além desta última, é também vantagem a maior exatidão das demonstrações e resultados contábeis, a qual também é do interesse do Fisco, assim como a maior observância da legislação aplicável (CREPALDI, CREPALDI, 2019). 
As atividades de auditoria devem seguir os ditames das Normas Brasileiras de Contabilidade (NBC) emitidas pelo Conselho Federal de Contabilidade (CFC), as quais são classificadas em Profissionais (NBCs PA) e Técnicas (NBCs TA). As primeiras estabelecem regras para o exercício profissional. Já as NBCs TA determinam conceitos, regras e procedimentos, em consonância com as normais internacionais de auditoria emitidas pela Internacional Federation of Accountants (IFAC). Além das NBCs, o CFC enuncia Comunicados Técnicos de Auditoria (CTA) para esclarecimentos de assuntos de natureza contábil em consideração aos interesses da profissão e da sociedade (PEREIRA, 2018).

Também fazem parte da regulamentação da matéria no Brasil, as leis ns. 6.404/76, 6.385/76, 11.638/07, entre outras; as resoluções emitidas pelo Banco Central do Brasil (Bacen) e pelo Conselho Nacional de Seguros Privados (CNSP), as instruções e deliberações da Comissão de Valores Imobiliários (CVM) e os pronunciamentos editados pelo Instituto dos Auditores Independentes do Brasil (IBRACON) (PEREIRA, 2018).

\subsection{Parecer ou Relatório do Auditor Independente}

O parecer ou relatório do auditor independente é o resultado das atividades de auditoria independente materializado em um documento no qual se apresenta a conclusão opinativa do auditor a respeito das demonstrações contábeis nele indicadas, de forma clara e objetiva.

Conforme a NBC TA 700, a estrutura do relatório do auditor independente deve conter as seções: Título, Destinatário, Opinião do auditor, Base para opinião, Continuidade operacional (quando aplicável), Principais assuntos de auditoria, Outras informações (quando aplicável), Responsabilidades da administração pelas demonstrações contábeis, Responsabilidades do auditor independente pela auditoria das demonstrações contábeis, Nome do sócio ou responsável técnico, Assinatura do auditor, Endereço do auditor independente e Data do relatório do auditor.

Ainda de acordo com a NBC TA 700, o auditor independente deve emitir uma opinião não modificada quando concluir que as demonstrações contábeis foram elaboradas em consonância com a estrutura de relatório financeiro aplicável, em todos os aspectos relevantes. 
Por seu turno, a NBC TA 705 dispõe que o auditor deve expressar uma opinião modificada quando constatar que as demonstrações contábeis como um todo apresentam distorções relevantes, com base em evidência de auditoria obtida; ou não conseguir obter evidência de auditoria apropriada e suficiente para concluir que as demonstrações contábeis não apresentam distorções relevantes como um todo. Ademais, este tipo de opinião abrange “Opinião com ressalva", "Opinião adversa" ou "Abstenção de opinião”, cuja diferenciação está explanada na tabela 1 a seguir.

Tabela 1: Natureza do assunto da opinião modificada

\begin{tabular}{l|l|l}
\hline $\begin{array}{l}\text { Natureza do assunto que } \\
\text { gerou a modificação }\end{array}$ & $\begin{array}{l}\text { Julgamento do auditor sobre a disseminação de forma } \\
\text { generalizada dos efeitos ou possíveis efeitos sobre as } \\
\text { demonstrações contábeis }\end{array}$ \\
\cline { 2 - 3 } & $\begin{array}{l}\text { Relevante, mas não } \\
\text { generalizado }\end{array}$ & Relevante e generalizado \\
\hline As demonstrações & Opinião com ressalva & Opinião adversa \\
contábeis apresentam & & \\
distorções relevantes & Abstenção de opinião \\
Impossibilidade de obter & Opinião com ressalva & \\
apropriada e suficiente & & \\
\hline
\end{tabular}

Fonte: Pereira et al., 2017

\section{METODOLOGIA}

O presente estudo é classificado como um levantamento de dados para fins exploratórios e descritivos na área de conhecimento da Auditoria. Deste modo, definiram-se como objeto de estudo os relatórios de auditoria independente sobre as demonstrações contábeis das empresas de capital aberto com ações negociadas na B3 referentes ao exercício de 2019 emitido até março de 2020, cuja totalidade desses relatórios refere-se a 403.

Realizou-se a classificação dos relatórios de auditoria independente sobre empresas analisadas por firma de auditoria independente, tipo de opinião do auditor e setor de atuação. Adicionalmente, descreveram-se as bases para opinião com ressalva e para abstenção de opinião. 


\section{RESULTADOS E DISCUSSÃO}

Inicialmente, fez-se o levantamento dos relatórios de auditoria sobre as demonstrações contábeis das companhias com ações na B3, emitidos com opiniões modificada e não modificada. Os números resultantes disso estão dispostos na tabela 2.

Tabela 2: Quantidades de relatórios de auditoria sobre as DC's das companhias negociadas na B3 por tipo de opinião

\begin{tabular}{c|c}
\hline Tipo de opinião & Quantidades \\
\hline Não modificada & 376 \\
\hline Com ressalva & 18 \\
\hline Abstenção & 9 \\
\hline Adversa & 0 \\
\hline Total & $\mathbf{4 0 3}$ \\
\hline
\end{tabular}

Fonte: dados do estudo de acordo com dados da B3.

É evidente que a maior parte dos relatórios de auditoria independente das companhias referentes ao exercício de 2019 foram emitidos com opinião não modificada. Os relatórios com opinião não modificada compõem cerca de $93,1 \%$ do total de relatórios sobre as demonstrações contábeis das empresas listadas na B3. Ainda sobre estas empresas, apenas $4,7 \%$ e $2,2 \%$ dos relatórios foram emitidos com ressalva e abstenção de opinião, respectivamente.

Salienta-se que nenhum relatório de auditoria independente sobre as demonstrações contábeis das empresas com ações na B3 foi emitido com opinião adversa.

Dando continuidade, determinou-se as quantidades de relatórios emitidos com opiniões modificada e não modificada por firmas Big Four e não Big Four. Esses dados estão expostos na tabela a seguir que traz a quantidade de relatórios com opinião não modificada e modificada emitidos por firmas de auditoria independente sobre as demonstrações contábeis de empresas não financeiras com ações na B3: 
Tabela 3: Opinião modificada e não modificada

\begin{tabular}{c|c|c|c}
\hline Firma & $\begin{array}{c}\text { Não } \\
\text { modificada }\end{array}$ & Com ressalva & Abstenção \\
\hline Deloitte & 30 & 1 & 0 \\
\hline E\&Y & 74 & 3 & 1 \\
\hline KPMG & 91 & 7 & 0 \\
\hline PwC & 62 & 0 & 1 \\
\hline Outras & 119 & 7 & 7 \\
\hline Total & $\mathbf{3 7 6}$ & $\mathbf{1 8}$ & $\mathbf{9}$ \\
\hline
\end{tabular}

Fonte: dados do estudo de acordo com dados da B3.

Por meio da Tabela 3, verifica-se que a maior parte dos relatórios sobre as demonstrações contábeis das empresas com ações negociadas na B3 com opinião não modificada é redigida pelas Big Four, com 257 relatórios contra 119 emitidos por firmas não Big Four. Por outro lado, 61\% dos relatórios com ressalva e apenas $22 \%$ daqueles com abstenção de opinião foram emitidos pelas Big Four.

Classificou-se, ainda, os relatórios de auditoria independente por setor de atuação das companhias negociadas na B3, conforme a tabela 4 que apresenta os tipos de opinião do auditor independente por setor de atuação das companhias negociadas na B3.

Tabela 4: Tipos de opinião

\begin{tabular}{c|c|c|c}
\hline Setor de atuação & $\begin{array}{c}\text { Não } \\
\text { modificada }\end{array}$ & Com ressalva & Abstenção \\
\hline Bens Industriais & 60 & 9 & 1 \\
\hline Comunicações & 6 & 0 & 0 \\
\hline Consumo Cíclico & 74 & 1 & 2 \\
\hline Consumo Não Cíclico & 20 & 1 & 1 \\
\hline Financeiro & 78 & 3 & 2 \\
\hline Materiais Básicos & 27 & 3 & 1 \\
\hline Outros & 15 & 0 & 0 \\
\hline Petróleo, Gás e Biocombustíveis & 8 & 1 & 0 \\
\hline Saúde & 18 & 0 & 0 \\
\hline Tecnologia da Informação & 7 & 0 & 2 \\
\hline Utilidade Pública & 63 & 0 & $\mathbf{9}$ \\
\hline Total & $\mathbf{3 7 6}$ & $\mathbf{1 8}$ & \\
\hline
\end{tabular}

Fonte: dados do estudo de acordo com dados da B3.

O setor Financeiro, cuja boa parte é constituída por bancos, exploradoras de imóveis e securitizadoras de recebíveis, foi o que mais teve empresas com relatórios de auditoria sem 
modificações na opinião, os quais representaram cerca de $20,7 \%$ do total de relatórios do tipo. Além disso, apenas três relatórios referentes às empresas financeiras contiveram ressalva e dois, com abstenção.

No que tange ao setor de Consumo Cíclico, constituído, principalmente, pelo segmento de Automóveis e Motocicletas, Aluguel de Carros, Construção Civil e de Fios e Tecidos, foram emitidos 74 relatórios com opinião não modificada, o que compõe 19,7\% dos relatórios com este tipo de opinião. Apenas três relatórios das demonstrações das companhias do setor apresentaram opinião modificada do auditor: um com ressalva e dois com abstenção.

Com mais relatórios emitidos com ressalvas, o setor de Bens Industriais era formado majoritariamente por empresas do segmento de Exploração de Rodovias e Transporte (Aéreo, Rodoviário e Ferroviário, principalmente). Deste modo, 37,5\% de todos os relatórios com opinião com ressalvas são do setor. Por outro lado, aproximadamente $16 \%$ dos casos nos quais o auditor expressou uma opinião sem modificações são de demonstrações contábeis de empresas de Bens Industriais.

Já o setor de Utilidade Pública era composto por 65 companhias negociadas na B3, das quais, em apenas duas, o auditor independente absteve-se de opinar. Dos 63 relatórios sem modificações na opinião, 56 são atinentes a companhias do segmento de Energia Elétrica, bem como aqueles dois relatórios com opinião modificada.

Já o setor de Materiais Básicos somou 31 relatórios, dos quais 27 com opinião não modificada, três com ressalva e um com abstenção. Esses três relatórios são relativos às empresas de Madeira e Papel, Siderurgia e Metalurgia e de Embalagens. Aquele último referiu-se a uma empresa atuante no ramo de Mineração. Todos os outros 27 relatórios atribuíram-se, sobretudo, a esses quatro segmentos também.

Um conjunto de 20 companhias fabricantes de bebidas, carnes e derivados, alimentos diversos, açúcar e álcool, produtos agropecuários e de produtos de uso pessoal e de limpeza, as quais compõem o setor de Consumo não Cíclico, apresentaram as demonstrações contábeis adequadamente. Apenas um relatório com ressalvas e outro com abstenção de opinião referentes, respectivamente, a companhias do segmento de Alimentos Diversos e da Agropecuária foram emitidos.

Os setores de Comunicações, Saúde, Tecnologia da Informação e Outros foram os únicos cuja totalidade das empresas atuantes apresentaram adequadamente suas 
demonstrações contábeis. Em outras palavras, nenhum relatório com opinião modificada sobre as empresas desses setores foi enunciado.

Quanto às empresas de Petróleo, Gás e Biocombustíveis, foram apresentados oito relatórios sem modificações na opinião e apenas um com ressalvas.

$\mathrm{Na}$ tabela a seguir, evidencia-se a frequência de cada base para opinião com ressalva nos relatórios de auditoria independente das companhias com ações negociadas na B3. Vale frisar que houve relatórios com mais de uma base para opinião. A tabela 5 explicita os motivos das ressalvas nos relatórios de auditoria independente das demonstrações contábeis das companhias negociadas na B3 emitidos com opinião modificada.

Tabela 5: Motivos das ressalvas

\begin{tabular}{c|c}
\hline Base para opinião com ressalva & Frequência \\
\hline A.V.P. da carteira de arrendamento mercantil & 2 \\
\hline Investigações de autoridades públicas em andamento/ informações sob segredo de justiça & 5 \\
\hline Exclusão do ICMS da base de cálculo do PIS e COFINS & 4 \\
\hline Passivo de benefício definido & 1 \\
\hline Ajuste ao valor recuperável de ativos & 2 \\
\hline Obrigações tributárias na esfera estadual pendentes de pagamento & 1 \\
\hline Empréstimos e Financiamentos & 2 \\
\hline Registro de Imposto de Renda e Contribuição Social diferidos ativos sobre base negativa e \\
prejuízo fiscal & 1 \\
\hline Incertezas relevantes relacionadas com a continuidade operacional & 3 \\
\hline Processo de apuração pela Receita Federal do Brasil de saldo efetivo de impostos e \\
contribuições federais devidos & 1
\end{tabular}

Fonte: dados do estudo de acordo com dados da B3

Observa-se que metade dos relatórios emitidos com ressalva, tiveram como razão as investigações de autoridades públicas e a exclusão do ICMS da base de cálculo do PIS e COFINS. Essas investigações, no momento da emissão do relatório, não estavam concluídas e, dessa forma, novas informações poderiam surgir ao término delas. Além disso, as empresas investigadas precisaram limitar o acesso dos auditores às suas informações contábeis e financeiras, já que algumas delas estavam sob segredo de justiça. No que pese à exclusão do ICMS da base de cálculo do PIS e COFINS, as empresas, apesar de obterem decisão judicial favorável transitada em julgado, não realizaram, de forma confiável, as estimativas do montante recuperável dos créditos tributários, ocasionando efeitos relevantes nas demonstrações contábeis, como a subavaliação da conta Impostos a Recuperar, do Patrimônio Líquido e do Lucro antes dos impostos. 


\section{能CAFI}

VITAL, Ivan Viana Araújo; ROCHA, Stephanie Kalynka. (2020) Análise dos relatórios de auditoria sobre as demonstrações contábeis das companhias listadas na B3 em 2019. Cafi, v. 4 n. 1, p. 23 - 37. ISSN 2595-1750

No caso do ajuste a valor presente da carteira de arrendamento mercantil, as diretrizes contábeis estabelecidas pelo Banco Central do Brasil requerem tais ajustes como provisão para superveniência ou insuficiência de depreciação. Entretanto, essas diretrizes não requerem a reclassificação das operações, registradas de acordo com as disposições da Lei $n^{\circ}$ 6.099/74, para as rubricas do ativo circulante e realizável a longo prazo, e rendas e despesas de arrendamento.

Quanto ao ajuste ao ajuste do valor recuperável de ativos, houve dois casos: em um deles, a empresa realizou esse ajuste de forma errônea e, por isto, o seu ativo imobilizado e o patrimônio líquido foram apresentados a maior e o prejuízo líquido do exercício, a menor. Somado a isso, o auditor independente determinou a existência de incertezas relevantes relacionadas com a continuidade operacional da empresa, decorrentes de prejuízos nos últimos exercícios. No segundo caso, a companhia não procedeu aos testes de impairment de acordo com o critério que, na opinião do auditor independente, seria o aplicável na situação. Ainda sobre este caso, o saldo efetivo de impostos e contribuições pela companhia encontrava-se em processo de apuração pela Receita Federal do Brasil, não sendo possível determinar o seu montante final. E não só isso, essa mesma companhia possuía empréstimos e financiamentos sujeitos a negociação, cujo efeito só seria conhecido ao término dela.

Já na outra situação na qual a base de opinião com ressalva foram os empréstimos e financiamentos, a empresa descumpriu determinadas cláusulas contratuais de determinados empréstimos e financiamentos e, levando-se em consideração que a entidade não possuía o direito de postergar a liquidação da obrigação em pelo menos 12 meses após a data final do exercício, a obrigação, na opinião do auditor, deveria ter sido classificada integralmente classificada no passivo circulante. Resultado disso: passivo circulante registrado a menor e passivo não circulante, a maior.

Ademais, foram emitidos 3 relatórios com incertezas relevantes relacionadas com a continuidade operacional. Um deles apresentou também as investigações de autoridades públicas em andamento como motivo para emissão de opinião ressalvada e um outro relatório, o ajuste do valor recuperável de ativos, os quais foram explanados anteriormente. O relatório restante teve como base para opinião com ressalva apenas aquelas incertezas.

Ainda houve uma empresa que divergiu dos critérios previstos na Deliberação CVM n 695/12 e na Resolução CMN no 4.424/15, ao definir parte do montante do valor líquido do passivo de benefício definido. 
Adicionalmente, uma companhia possuía obrigações tributárias na esfera estadual pendentes de pagamento e atualização por conta do processo de negociação com os Estados, impossibilitando, consequentemente, concluir quanto aos possíveis impactos em suas demonstrações.

Verifica-se que existiu um relatório com ressalva quanto ao registro de Imposto de Renda e Contribuição Social, os quais foram diferidos ativos sobre base negativa e prejuízo fiscal nas demonstrações contábeis da companhia, a qual não atendeu cumulativamente as condições de apresentação de histórico de rentabilidade e expectativa de geração de lucros tributáveis futuros em conformidade com a Instrução 371/2002 da CVM e a NBC TG 32 Tributos sobre o Lucro.

A tabela 6 expõe a frequência de cada base para abstenção de opinião nos relatórios de auditoria independente das companhias com ações negociadas na B3. É importante destacar que existiram relatórios com mais de uma base.

A tabela 6 evidencia os motivos das abstenções de opinião nos relatórios de auditoria independente das demonstrações contábeis das companhias negociadas na B3 emitidos com opinião modificada.

Tabela 6: Abstenções de opinião

\begin{tabular}{c|c}
\hline Base para abstenção de opinião & Frequência \\
\hline Recuperação Judicial & 7 \\
\hline Recuperação Extrajudicial & 1 \\
\hline Incertezas relevantes sobre a continuidade operacional & 4 \\
\hline Valor recuperável de ativos & 2 \\
\hline Limitação/inacesso a informações contábeis & 2 \\
\hline Prejuízo do exercício anterior superavaliado & 1 \\
\hline
\end{tabular}

Fonte: dados do estudo de acordo com dados da B3.

Evidencia-se que a maior parte dos relatórios apresentou a recuperação judicial como base para abstenção de opinião. Isso significa que algumas companhias ajuizaram ou protocolaram pedido de recuperação judicial. Assim, 4 dessas companhias tiveram o plano de recuperação aprovado em assembleia de credores, uma ainda estava com o plano em elaboração, uma outra com o plano em fase de apresentação e discussão com os credores e stakeholders e, por fim, a companhia restante não teve o plano de recuperação aprovado em assembleia. 


\section{哭 CAFI}

VITAL, Ivan Viana Araújo; ROCHA, Stephanie Kalynka. (2020) Análise dos relatórios de auditoria sobre as demonstrações contábeis das companhias listadas na B3 em 2019. Cafi, v. 4 n. 1, p. 23 - 37. ISSN 2595-1750

Além disso, uma companhia protocolou pedido de recuperação judicial, após a extinção do plano de recuperação extrajudicial e, em decorrência dos indeferimentos do Poder Judiciário competente ocorridos em relação ao plano, não possível ao auditor independente concluir sobre os efeitos disso sobre os saldos do ativo, passivo e componentes da demonstração do resultado e quanto à continuidade operacional da entidade.

É interessante ressaltar que todos os casos de incertezas relevantes sobre a continuidade operacional constituíram-se em decorrência da recuperação judicial das companhias. Em outras palavras, foram emitidos 4 relatórios com essas incertezas e a recuperação judicial, em conjunto, como base para abstenção de opinião. Além disso, em um desses casos, houve ainda a limitação de acesso às informações contábeis de empresas controladas e a superavaliação do prejuízo do exercício anterior, bem como um outro caso no qual não foi possível aos auditores determinar o valor recuperável de certos ativos da empresa.

Já a ocorrência do segundo caso deste último tipo de base para abstenção de opinião também foi motivada pela impossibilidade de revisão e determinação do montante da perda por desvalorização de alguns ativos da empresa, destacando-se ainda que simultaneamente a isso, a empresa estava em recuperação judicial e com o plano de recuperação em fase de elaboração, o que foi citado anteriormente.

E finalmente, em uma das companhias, o auditor independente não conseguiu ter acesso às informações contábeis de empresas coligadas, o que, por si só, justificou abstenção de opinião.

\section{CONSIDERAÇÕES FINAIS}

Verificou-se que a maior parte das empresas listadas na B3 tiveram suas demonstrações auditadas por uma das firmas pertencentes à Big Four, as quais emitiram 257 relatórios com opinião não modificada, de um total de 376, e 13 dos 27 relatórios com opinião modificada. Além disso, apenas 6,7\% dos relatórios de auditoria independente das companhias apresentaram opinião modificada, sendo 4,5\% com opinião com ressalva e 2,2\% com abstenção de opinião.

O setor com o maior número de companhias auditadas foi o Financeiro, seguido pelos setores de Consumo Cíclico e de Bens Industriais. Apenas estes setores representaram mais da 


\section{能CAFI}

VITAL, Ivan Viana Araújo; ROCHA, Stephanie Kalynka. (2020) Análise dos relatórios de auditoria sobre as demonstrações contábeis das companhias listadas na B3 em 2019. Cafi, v. 4 n. 1, p. 23 - 37. ISSN 2595-1750

metade das empresas auditadas, com 212 relatórios emitidos com opinião não modificada, 13 com ressalvas e apenas 5 com abstenção de opinião.

Fatos como investigações de autoridades públicas em andamento/ informações sob segredo de justiça, exclusão do ICMS da base de cálculo do PIS e COFINS e incertezas relevantes relacionadas com a continuidade operacional motivaram a maior parte das ressalvas nos relatórios de auditoria. Os ajustes a valor presente da carteira de arrendamento mercantil e ao valor recuperável de ativo, bem como empréstimos e financiamentos foram algumas das outras bases para opinião com ressalvas. Não custa lembrar que houve relatórios com dois ou mais desses fatos como base para opinião.

Adicionalmente, verificou-se que recuperação judicial e incertezas relevantes sobre a continuidade operacional constituíram boa parte das bases para abstenção de opinião. $\mathrm{O}$ valor recuperável de ativos, limitação ao acesso a informações contábeis, prejuízo do exercício anterior superavaliado e recuperação extrajudicial também justificaram a abstenção de opinião. Vale ressaltar que, assim como nos casos de ressalvas, existiram relatórios com mais de uma base.

\section{REFERÊNCIAS}

Almeida, Marcelo Cavalcanti. (2019). Auditoria: abordagem moderna e completa. 9. ed. São Paulo, Atlas.

Camargo, Raphael Vinicius Weigert. (2012). Determinantes Dos Pareceres Dos Auditores Independentes Emitidos Às Companhias Negociadas Na Bm\&Fbovespa. Dissertação de Mestrado em Contabilidade. UFSC.

Conselho Federal de Contabilidade (CFC). NBC TA 200 (R1): Objetivos Gerais do Auditor Independente e a Condução da Auditoria em Conformidade com Normas de Auditoria. Recuperado em 20 junho, 2020, de https://cfc.org.br/tecnica/normas-brasileiras-decontabilidade/nbc-ta-de-auditoria-independente/.

Conselho Federal de Contabilidade (CFC). NBC TA 700: Formação da Opinião e Emissão do Relatório do Auditor Independente sobre as Demonstrações Contábeis. Recuperado em 20 junho, 2020, de https://cfc.org.br/tecnica/normas-brasileiras-decontabilidade/nbc-ta-de-auditoria-independente/.

Conselho Federal de Contabilidade (CFC). NBC TA 705: Modificações na Opinião do Auditor Independente. Recuperado em 20 junho, 2020, de https://cfc.org.br/tecnica/normas-brasileiras-de-contabilidade/nbc-ta-de-auditoriaindependente/.

Crepaldi, Silvio Aparecido; Crepaldi, Guilherme Simões. (2019). Auditoria Contábil: teoria e prática. 11. ed. São Paulo, Atlas. 
Damascena, Luzivalda Guedes; Paulo, Edilson. (2013). Pareceres De Auditoria: Um Estudo Das Ressalvas E Parágrafos De Ênfase Constantes Nas Demonstrações Contábeis Das Companhias Abertas Brasileiras. Revista Universo Contábil. v. 9, n. 3, p. 104-127. Blumenau.

Damascena, L. G.; Firmino, J. E.; Paulo, E. (2011). Estudo sobre os pareceres de auditoria: análise dos parágrafos de ênfase e ressalvas constantes nas demonstrações contábeis das companhias listadas na Bovespa. Contabilidade Vista \& Revista, v. 22, n. 2, p. 125-154.

Garçon, Juliana. (2012). Empresas ignoram lei sobre auditoria externa. Ibracon na Mídia. Disponível em: <http://www.ibracon.com.br/ibracon/Portugues/detNoticia.php?cod=506> Acesso em: 30 jun. 2020.

Gramling, Audrey; Rittenberg, Larry; Johnstone; Karla. (2011). Auditoria. Tradução de Antonio Zoratto Sanvicente. 7 ed. Cengage Learning.

Leone, Arthur. (2018). Auditoria para Concursos: Teoria e questões comentadas. 2. ed. Rio de Janeiro, Ferreira.

Pereira, Alexandre Demetrius. (2018). Auditoria das Demonstrações Contábeis. 2. ed. São Paulo, Saraiva.

Pereira, Fernando Rocha; Machado, Nathan Vasconcellos de Almeida Rezende Machado; Pinheiro, Laura Edith Taboada; Dutra, Saulo Ribeiro. (2017). Auditoria Contábil: Um estudo acerca da relação entre o relatório dos auditores e as características da empresa auditada. XIV Congresso USP de Iniciação Científica em Contabilidade. São Paulo.

Santana, André Gobette; Bezerra, Francisco Antonio; Teixeira, Silvio Aparecido; Cunha, Paulo Roberto da. (2014). Auditoria Independente E A Qualidade Da Informação Na Divulgação Das Demonstrações Contábeis: Estudo Comparativo Entre Empresas Brasileiras Auditadas Pelas Big Four E Não Big Four. Revista de Contabilidade do Mestrado em Ciências Contábeis da UERJ. v. 19, n. 3, p. 70-87. Rio de Janeiro. 